\title{
Pregnancy alters nitric oxide synthase and natriuretic peptide systems in the rat left ventricle
}

\author{
M Jankowski, D Wang, S Mukaddam-Daher and J Gutkowska \\ Laboratory of Cardiovascular Biochemistry, Centre de recherche, Centre hospitalier de l'Université de Montreal (CHUM) Montreal, Quebec, Canada \\ (Requests for offprints should be addressed to Marek Jankowski, Centre de recherche du CHUM-Hôtel-Dieu, Pavillon de Bullion (6-816), 3840 rue \\ Saint-Urbain, Montreal, Quebec, Canada, H2W 1T8; Email: marek.jankowski@umontreal.ca)
}

\begin{abstract}
Cyclic guanosine monophosphate (cGMP), which is implicated in cardiac cell growth and function, is synthesized by cytoplasmic soluble guanylyl cyclase (GC) stimulated via nitric oxide $(\mathrm{NO})$ and by particulate membrane-bound GC activated via natriuretic peptides. We investigated possible cGMP elevation in the left ventricle (LV) of rats developing physiologic LV hypertrophy during gestation. Furthermore, expression of estrogen receptors (ER) and oxytocin receptors (OTR) was evaluated because their activation stimulates $\mathrm{NO}$ and atrial natriuretic peptide (ANP) release from the heart. Compared with nonpregnant controls, Sprague-Dawley rats on day 7 of gestation had similar heart weights, but, on days 14 and 21 , ventricular mass increased by $12 \%$ and $28 \%$ respectively $(P<0 \cdot 05)$. LV cGMP concentration was elevated at day 14 of gestation $(3 \cdot 25 \pm 0 \cdot 12$ vs $4 \cdot 65 \pm 0 \cdot 17 \mathrm{pmol} / \mathrm{g}$ wet weight, $P<0 \cdot 01)$ but decreased at day $21 \quad(2 \cdot 45 \pm$ $0.09 \mathrm{pmol} / \mathrm{g}, P<0.05)$ to increase again on postpartum
\end{abstract}

day $1(6 \cdot 01 \pm 0 \cdot 15 \mathrm{pmol} / \mathrm{g})$ and day $4(9 \cdot 21 \pm 1 \cdot 79 \mathrm{pmol} /$ g). Changes in endothelial nitric oxide synthase (eNOS), inducible NOS (iNOS), OTR and ER $\alpha$, but not ER $\beta$, proteins paralleled the pregnancy-related cGMP changes in the LV. In contrast, ANP mRNA of the LV remained at control level throughout gestation but increased postpartum, whereas brain natriuretic peptide (BNP) expression declined at term and increased postpartum. The particulate GC natriuretic peptide receptors (GC-A and GC-B) transcripts were already lower at day 14 of gestation. Natriuretic peptide clearance receptor (NPR-C) transcript was not altered on days 7 and 14, but increased at term. We conclude that cGMP concentration in the rat LV is influenced by both NOS and natriuretic peptide systems and may be involved in the changes of LV contractility and hypertrophy that occur during rat gestation.

Journal of Endocrinology (2005) 184, 209-217

\section{Introduction}

In the rat, maternal cardiovascular adaptation to pregnancy is initiated 2 days after implantation and is manifested by expanded stroke volume as well as increased heart contractility (Slangen et al. 1997). In effect, pregnancy triggers physiologic left ventricular (LV) hypertrophy and atrophy secondary to a transient, self-limited hemodynamic load, making the heart mechanically more efficient. The importance of these alterations becomes evident in preeclampsia when cardiac hypertrophy is exaggerated, and its resolution remains incomplete after parturition (Simmons et al. 2002).

In response to elevated female steroid hormones during gestation, cardiac growth and contractility are modulated profoundly in parallel with changes in various hormones, electrolyte balance, blood volume and blood pressure (Granger 2002). Estrogens regulate cardiac hypertrophy by direct effects on the heart and by triggering the release of cardioprotective factors. Estrogen stimulates nitric oxide synthase (NOS) in various organs, including cardiac tissue, in association with an increase of cyclic guanosine monophosphate (cGMP) (Weiner et al. 1994), the second messenger of nitric oxide (NO). Three different isoforms of NOS catalyze the oxidation of L-arginine to citrulline and NO: endothelial (eNOS), neuronal (nNOS), and inducible (iNOS) NOS. Myocardial eNOS appears to be important under physiologic conditions in pregnancy, where it is involved in cardiac hypertrophy (Trochu et al. 2000). eNOS knockout mice develop the hypertrophic phenotype by 5 months of age, manifested as increased wall thickness (Barouch et al. 2002). Interestingly, cGMP levels in the LV are unaffected by eNOS gene knockout because of compensation of its synthesis by upregulated atrial natriuretic peptide (ANP) (Gyurko et al. 2000), indicating an interaction between NOS and natriuretic peptide systems in the LV.

ANP and brain natriuretic peptide (BNP) are mainly produced in cardiac atria and ventricles respectively, and both are released into the circulation and influence 
blood volume and pressure. Cardiac ANP expression is influenced by elevated estradiol during pregnancy and postpartum (Jankowski et al. 2001, Mukaddam-Daher et al. 2002). Brown et al. (1993) have shown that the transcriptional downregulation of heart natriuretic peptide receptors is associated with the development of hypertrophic cardiac pathology in the rat. Two natriuretic peptide receptors, guanylyl cyclase (GC)-A and GC-B (also known as NPR-A and NPR-B), are signal-transducing, single-pass transmembrane glycoproteins exhibiting ligand-dependent intrinsic GC activity (Tremblay et al. 2002, Kuhn 2003). ANP and BNP have been shown to bind preferentially to GC-A, while C-type NP (CNP) displays a greater affinity for GC-B (Koller et al. 1991, Suga et al. 1992). A third receptor, NPR-C, lacks the GC domain, and modulates natriuretic peptide concentration through local metabolism (Nakao et al. 1993). The GC-A system has intrinsic growth inhibitory properties in cardiac fibroblasts (Cao \& Gardner 1995), and ANP and BNP inhibit cardiac ventricular myocyte hypertrophy to a greater extent than NO (Horio et al. 2000), independently of blood pressure (Kishimoto et al. 2001). It is noteworthy that inactivation of GC-A, resulting in hypertension, cardiac hypertrophy and increased mortality, evokes gender disparity, suggesting a protective action of estrogen (Vuolteenaho \& Ruskoaho 2003). Although the natriuretic peptide system is recognized as a critical factor in the control of cardiac hypertrophy (de Bold et al. 2001), few studies have investigated this action during pregnancy.

The purpose of this study was, therefore, to investigate the expression of natriuretic peptides, NOS and cGMP in the rat LV throughout gestation and early postpartum. Because of their contribution to ANP and NO release in the cardiovascular system, estrogen and oxytocin receptors (OTR) were also evaluated (Gutkowska et al. 1999, Jankowski et al. 2001, Mukaddam-Daher et al. 2001, Wang et al. 2003). Our results demonstrate that cGMP concentration in the rat LV is controlled by both NOS and natriuretic peptides, but their inverse expressions at different stages of gestation suggest distinct roles in the control of physiologic cardiac hypertrophy.

\section{Materials and Methods}

\section{Animals}

These experiments were performed in accordance with the Guidelines of the Canadian Council on Animal Care, after approval of the animal care committee of the Centre hospitalier de l'Université de Montréal. Female SpragueDawley rats purchased from Charles River (St Constant, QC, Canada) were housed in a temperature- and lightcontrolled room with food and water available ad libitum. Age-matched virgin and pregnant animals were weighed and killed by decapitation at days 7, 14 or 21 (term) of gestation, and at days 1 or 4 postpartum. Hearts were quickly removed, dissected, and blotted dry. Heart atria and ventricles were separately weighed, and then frozen in liquid nitrogen, and stored at $-80^{\circ} \mathrm{C}$ for RNA or protein extraction.

\section{Ventricular cGMP assay}

Measurement of cGMP concentration has already been described (Gutkowska et al. 1999). Briefly, the dissected tissues were cut into small pieces and homogenized in 5 vol of ice-cold $5 \%(\mathrm{v} / \mathrm{v})$ trichloroacetic acid (TCA). The homogenates were centrifuged at $600 \mathrm{~g}$, for $5 \mathrm{~min}$, at $4{ }^{\circ} \mathrm{C}$. TCA was extracted from the reaction mixture with 1:1 triocytydylamine and 1,1,2-trichlorofluoroethane (Sigma). cGMP concentration of the aqueous phase was quantified by radioimmunoassay, as described previously (Gutkowska et al. 1999), and expressed as picomoles per wet tissue weight in grams. The intra- and interassay coefficients of variation of this assay were $8 \%$ and $15 \%$ respectively.

\section{Northern blot analysis}

RNA was extracted from the LV with Trizol (Life Technologies, Gaithersburg, MD, USA), according to the manufacturer's instructions. Total RNA was subjected to electrophoresis on $1.5 \%$ agarose gels containing $0.22 \mathrm{M}$ formaldehyde and transferred onto nylon membranes (Hybond $\mathrm{N}+$; Amersham) by capillary blotting. Immobilized RNA samples were hybridized with randomly primed ${ }^{32} \mathrm{P}-\mathrm{cDNA}$ probes corresponding to ANP and alphatubulin mRNA sequences. The probes were labeled with a random priming kit (Gibco BRL, Bethesda, MD, USA) and ${ }^{32} \mathrm{P}-\mathrm{dCTP}$ (3000 Ci/mmol; Amersham). The Pst 1-digested 660-bp fragment from plasmid clone PN-1-11 served as the ANP probe (a gift from Dr Mona Nemer, Institut de Recherches Cliniques de Montréal, Montreal, QC, Canada).

\section{Complementary DNA synthesis and semiquantitative polymerase chain reaction (PCR)}

Total RNA was reverse transcribed by Moloney murine leukemia virus reverse transcriptase $(200 \mathrm{U}$; Life Technologies), with random primers $(200 \mathrm{ng})$ in a $20 \mu \mathrm{l}$ reaction mixture. To compare different expression levels, semiquantitative PCR was performed. A volume of $10 \mu \mathrm{l}$ first-strand cDNA was added to a PCR mixture and amplified for $25-35$ cycles by incubation at $95^{\circ} \mathrm{C}$ for $1 \mathrm{~min}$, at $57-65^{\circ} \mathrm{C}$ for $1 \mathrm{~min}$, and at $72{ }^{\circ} \mathrm{C}$ for $1.5 \mathrm{~min}$, with a final incubation at $72{ }^{\circ} \mathrm{C}$ for $3 \mathrm{~min}$, all in a Robocycler gradient 40 thermocycler (Stratagene, La Jolla, CA, USA). The RT reaction products were subjected to PCR amplification with the following primers:

- ANP forward, 5'-CAGCATGGGCTCCTTCTC CA-3' 
- ANP reverse, 5'-GTCAATCCTACCCCCGAA GCAGCT-3'

- BNP forward, 5'-CCATCGCAGCTGCCTGGCC CATCACTTCTG-3'

- BNP reverse, 5'-GACTGCGCCGATCCGGTC-3'

- GC-A forward, 5'-AAGCTTATCTGGAGGAGA AGCGCA-3'

- GC-A reverse, 5'-TCAGCCTCGAGTGCTACA TCCCCG-3'

- GC-B forward, 5'-GCTACATGGTACCACCAT

ATTTGGACAACCTC-3'

- GC-B reverse, 5'-CAGGAGTCCAGGAGGTCC TTTTCG-3'

- NPR-C forward, 5'-ATCGTGCGCCACATCCA GGCCAGT-3'

- NPR-C reverse, 5'-TCCAAAGTAATCACCAAT AACCTCCTGGGTACCCGC-3'.

The specificity of the amplified products was verified by sequencing. Amplification of $18 \mathrm{~S}$ RNA, used as an internal standard, followed the manufacturer's protocol (Ambion, Austin, TX, USA). PCR products were fractionated onto $1 \cdot 2 \%$ agarose gels containing ethidium bromide. The signal intensities were measured in at least eight individual animals with two independent reverse transcriptions (RT) per sample. The intensity of the bands was determined by densitometry with Molecular Imaging Software (Image-Quant Software, Molecular Dynamics, Sunnyvale, CA, USA). To validate this RT-PCR assay as a tool for the semiquantitative measurement of mRNA, dose-response curves were established for different amounts of total RNA extracted from the rat LV, and the samples were quantified in the curvilinear phase of PCR amplification. The expression levels were normalized against $18 \mathrm{~S}$ or GAPDH. No difference was observed in $18 \mathrm{~S}$ or GAPDH levels at any stage.

\section{Western blot analysis}

Western blot analysis was conducted as described elsewhere (Wang et al. 2003). Proteins were separated on an $8 \%$ sodium dodecyl sulfate gel and electrotransferred to nitrocellulose membranes (Hybond-C; Amersham Pharmacia Biotech, Baie d'Urfé, QC, Canada). Unbound sites were blocked overnight at $4^{\circ} \mathrm{C}$ with $10 \%(\mathrm{w} / \mathrm{v})$ nonfat milk in Tris-buffered saline containing $20 \mathrm{mmol} / 1$ Tris$\mathrm{HCl}(\mathrm{pH} 8 \cdot 0), 140 \mathrm{mmol} / 1 \mathrm{NaCl}$ and $0.05 \%$ (w/v) Tween-20. The membranes were then probed with mouse monoclonal antibodies for iNOS or eNOS (BD Biosciences, San Jose, CA, USA). OTR were investigated with rabbit polyclonal antibodies (generous gift from Dr Kate Whittington, University of Bristol, UK), and estrogen receptors using rabbit polyclonal antibody (Research Diagnostics, Pleasant Hill, NJ, USA). The membranes were washed and incubated with secondary antibodies linked to horseradish peroxidase-labeled antimouse or antirabbit immunoglobulin G (Amersham Pharmacia Bio- tech) for $2 \mathrm{~h}$. The blots were developed in an enhanced chemiluminescence system (Amersham Pharmacia Biotech) and visualized by exposure to Kodak radiographic film. The accuracy of protein loading on the gel was verified by reprobing with rabbit $\beta$-actin antibody and protein coloration on the membranes. Density of bands was measured with the Scion program $(\mathrm{NIH}$, Bethesda, MD, USA).

\section{Immunocytochemistry (ICC)}

Prior to ICC, OTR and ER antigenic sites were retrieved by immersing the sections in citrate buffer $0 \cdot 1 \mathrm{M}, \mathrm{pH} 6 \cdot 0$, heated to $90{ }^{\circ} \mathrm{C}$ for $20 \mathrm{~min}$ and allowed to cool slowly to room temperature. For incubation, primary antibodies diluted 1/300 in blocking solution (No. 00-8020; Zymed Laboratories, San Francisco, CA, USA) were revealed by the biotin-streptavidin method (No. 95-999, HistostainDS; Zymed Laboratories) (Jankowski et al. 2004). Controls obtained by the omission of primary antibodies were negative, emphasizing the specificity of ICC.

\section{Statistical analysis}

The data are expressed as mean \pm S.E.M. Normalized data of nonpregnant, pregnant and postpartum groups were compared by ANOVA, followed by Dunnett's test or, in the case of comparison with only one group, by a two-tailed version of Student's $t$-test. $P<0.05$ was accepted as the level of significance. For calculations, Prism 3 program was applied (GraphPad Software, San Diego CA, USA).

\section{Results}

Changes in body and heart weights during rat gestation

Table 1 shows that, compared with nonpregnant controls, rat body weight increased on gestational days $14(223 \pm 3$ to $264 \pm 6 \mathrm{~g}$ or $118 \% ; P<0 \cdot 05)$ and $21(412 \pm 8 \mathrm{~g}, 184 \%$; $P<0 \cdot 001)$. LV mass increased in a similar manner. Figure 1 shows a positive correlation between LV weight and body weight. On gestational day 14 , mean LV weight was $755 \mathrm{mg}$ (112\% of nonpregnant levels), and was further increased to $866 \mathrm{mg}(128 \%)$ on day 21. As shown in Table 1 , body weight remained above the control value on days 1 and 4 postpartum (127\% and 132\% respectively), and was associated with increments in ventricular weight $(127 \%$ and $123 \% ; P<0 \cdot 05)$. A positive correlation $(r=0 \cdot 81$ and 0.73 , respectively) between $\mathrm{LV}$ weight and body weight was found.

Atrial weight was not significantly altered and, on day 21 of gestation, represented $97 \cdot 5 \%$ of nonpregnant control levels. The elevation of atrial weight started in the postpartum period, and was significantly higher $(118 \%)$ on day 4 than in the nonpregnant controls. 
Table 1 Body weight (BW) and heart weight in rats at different days of gestation and early postpartum

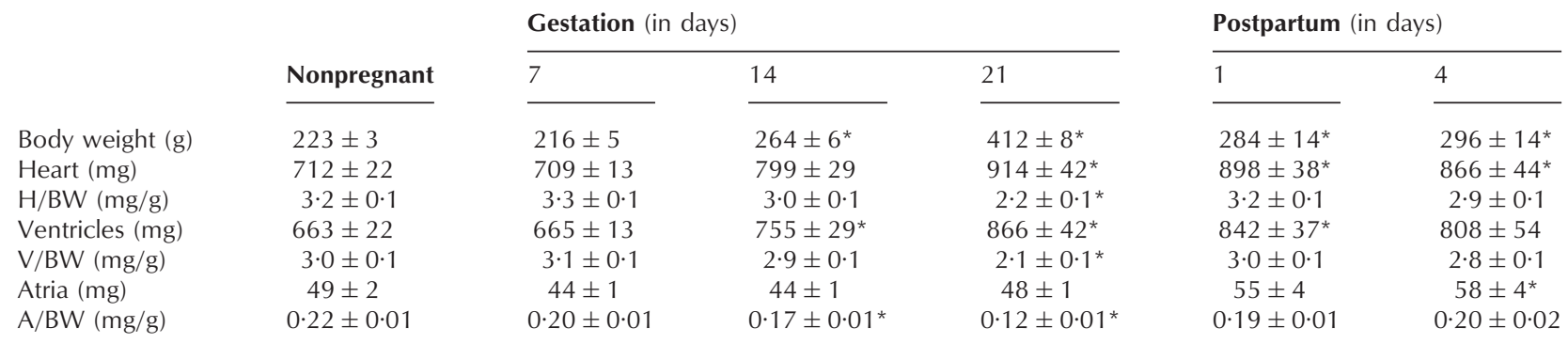

Values are mean \pm S.E.M. $n=8 .{ }^{*} P<0 \cdot 05$ vs non pregnant.

$\mathrm{H}$ : heart; V: Ventricles; A: Atria.

cGMP concentration in the LV of nonpregnant and pregnant rats

Compared with nonpregnant rats, cGMP concentration was highest in the LV on day 14 of gestation $(2.98 \pm$ 0.05 vs $4.65 \pm 0.17 \mathrm{pmol} / \mathrm{g}$ wet weight) and then decreased at term to $2 \cdot 32 \pm 0 \cdot 10 \mathrm{pmol} / \mathrm{g}$. cGMP concentration in the LV was elevated on postpartum days 1 and $4(6 \cdot 01 \pm 0 \cdot 15$ and $9 \cdot 21 \pm 1 \cdot 79 \mathrm{pmol} / \mathrm{g}$ respectively) (Fig. 2).
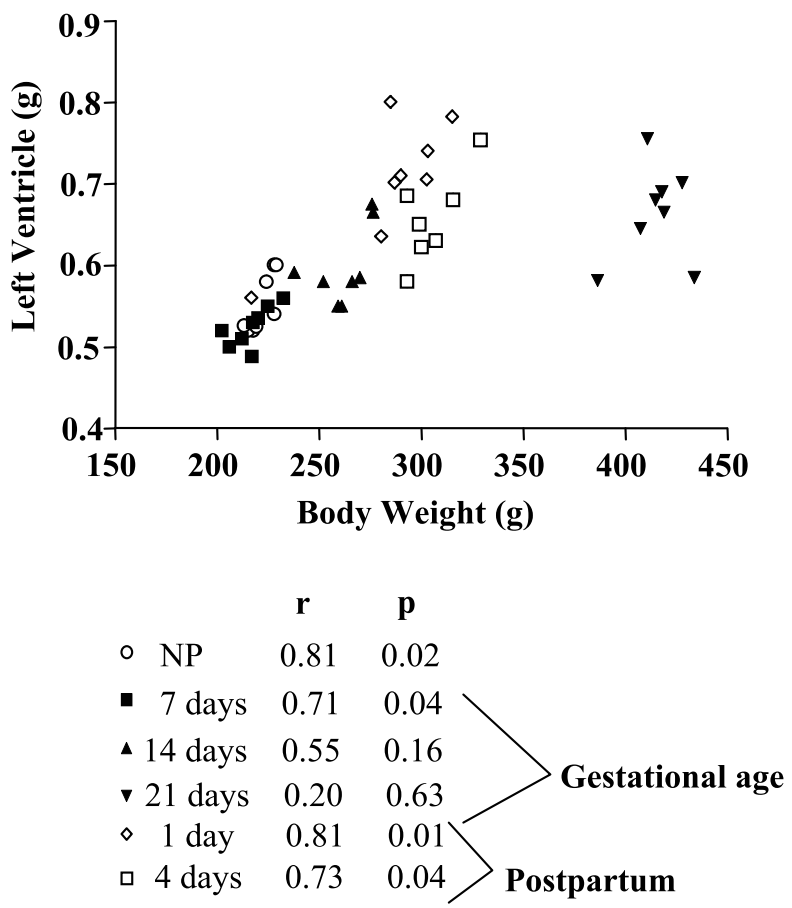

Figure 1 Correlation of changes in left ventricular weight and body weight on different days of rat gestation and early postpartum ( $n=8$, each group; $r=$ Pearson correlation coefficient, $P=$ significance value).
Western blot analysis of eNOS, iNOS, ER and OTR

In parallel with gestation-associated changes in LV cGMP levels, changes in OTR, iNOS and eNOS proteins were observed. Figure 3 shows that OTR (67 kDa)-, iNOS $(135 \mathrm{kDa})$ - and eNOS (140 kDa)-specific proteins in the LV were elevated on days 7 and 14 of pregnancy as compared with nonpregnant controls. However, at term, the expression of these proteins was decreased three to four times below LV levels in nonpregnant controls, and then increased after parturition, to exceed control values on postpartum day 4. As presented in Fig. 4, the ER $\alpha$ were slightly higher on gestational day 14 (35\%), but were below control level $(-60 \%)$ at postpartum. Western blot analysis detected no changes in ER $\beta$ during pregnancy and postpartum.

Figure 5 shows immunolocalization of OTR around the uterine lumen, within epithelial cells (small arrow), uterine glands (medium arrow) and myometrial smooth

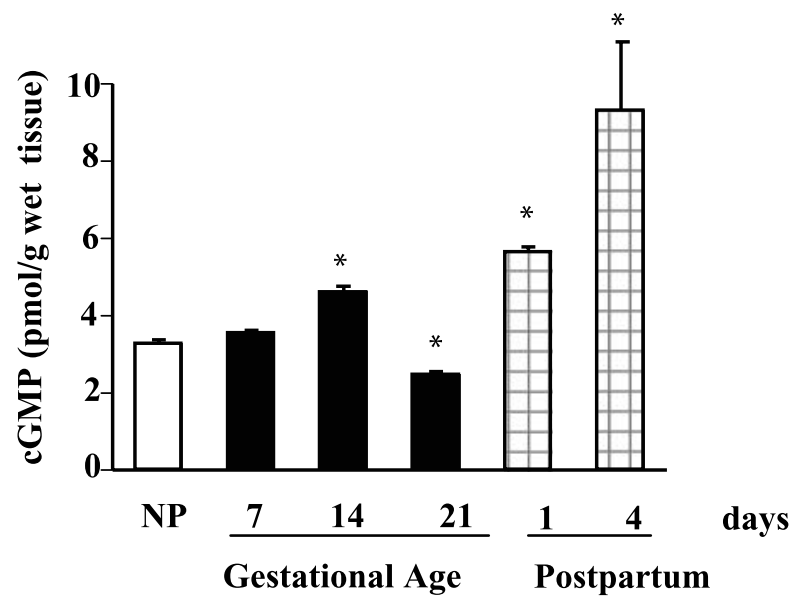

Figure 2 cGMP concentration in left ventricles of nonpregnant (NP), and pregnant rats at different stages of gestation and postpartum rats ( $n=5-6$ rats per group). Values are mean \pm S.E.M. ${ }^{\star} P<0.05$ vs NP. 


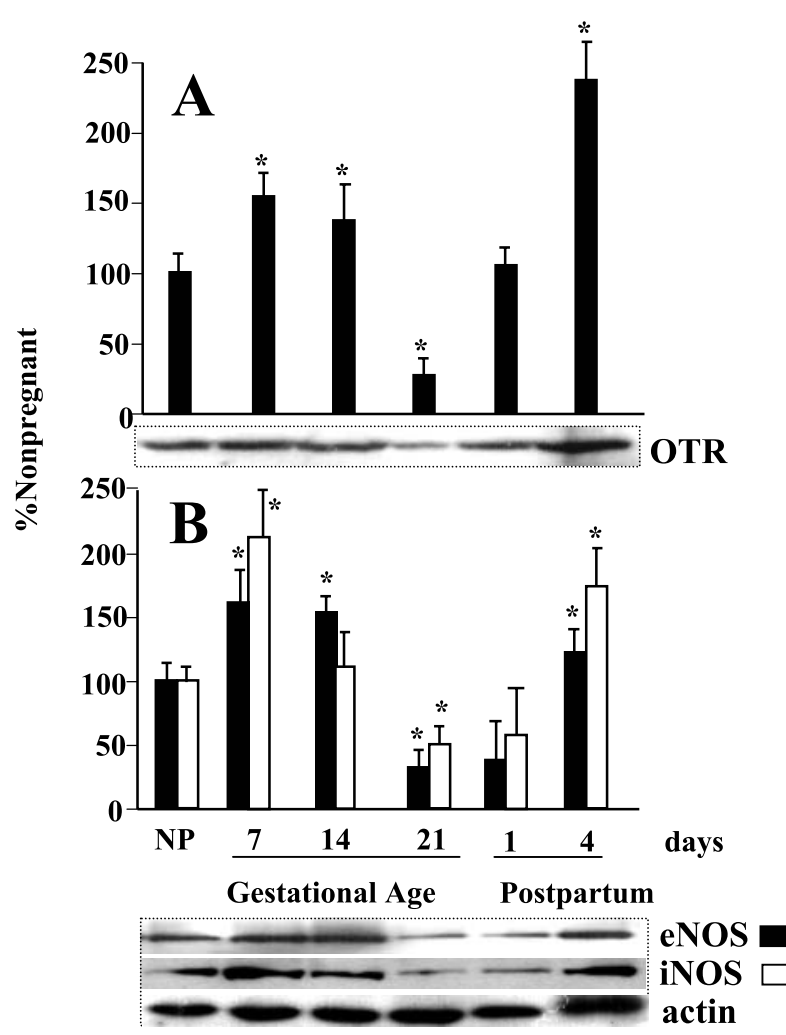

Figure 3 Western blot analysis of (A) oxytocin receptors (OTR), and (B) endothelial (eNOS) and inducible (iNOS) nitric oxide synthases in left ventricles of rats during gestation and early postpartum. Representative immunoblot shows OTR (67 kDa), eNOS (140 kDa) and iNOS (135 kDa). Band optical density was adjusted to the corresponding actin band and expressed as a percentage of the nonpregnant (NP) value obtained in the same experiment. Three independent experiments gave similar results $\left({ }^{*} P<0 \cdot 05\right.$ vs NP).

muscles (large arrow). ER $\alpha$ immunoreactivity was also detected in cell nuclei of atrial cardiomyocytes (arrows in Fig. 5C). Much lower ER $\alpha$ immunoreactivity could be detected in the heart ventricle (Fig. 5D). These results, confirming already known sites of OTR and ER $\alpha$ expression, indicate antibody specificity. In addition, no $\operatorname{ER} \beta$ staining was observed in the rat heart sections.

\section{Expression of natriuretic peptides}

ANP mRNA expression in LV was not altered throughout gestation (Fig. 6A), but significantly increased postpartum. The results obtained by RT-PCR confirmed the Northern blot analysis and showed twofold increase in ANP mRNA in the LV of postpartum rats (Fig. 6B). Similarly, RT-PCR analysis revealed that BNP mRNA was unchanged on day 7 , and then decreased to $60 \%$ by day 14 , and further to $10 \%$ at term, as compared with

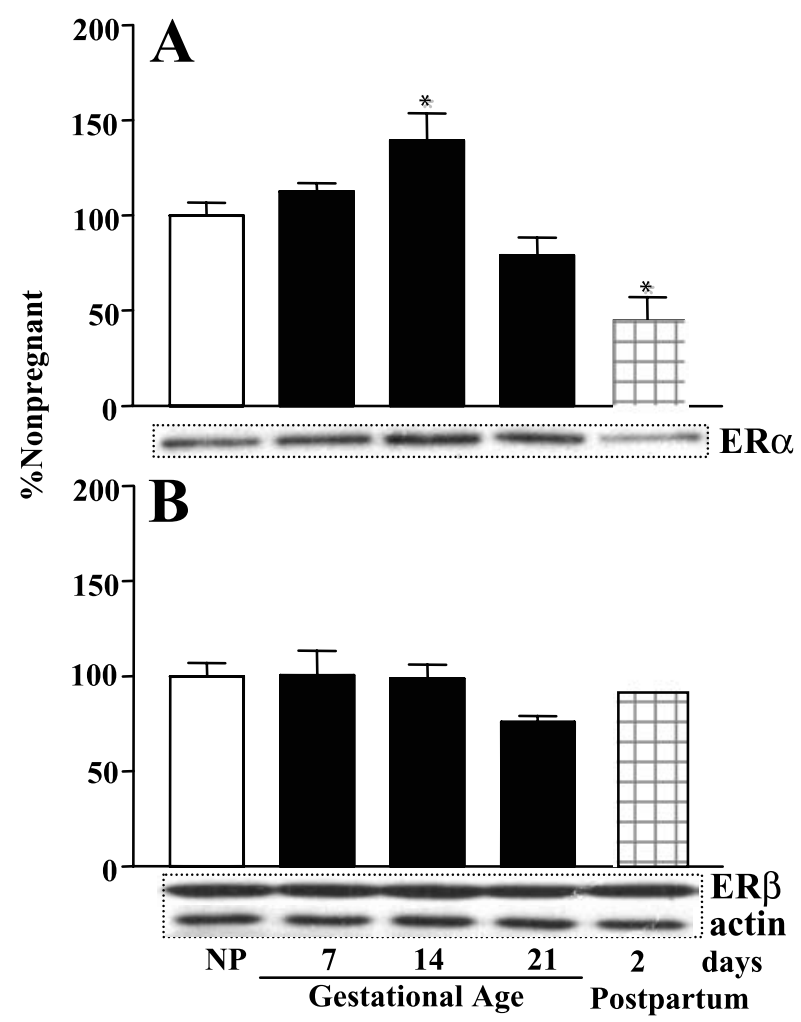

Figure 4 Western blot analysis of estrogen receptors $\alpha$ (ER $\alpha)$ (A) and $\beta$ (ER $\beta)(B)$ in left ventricles of rats during gestation and early postpartum. Representative immunoblot shows ER $\alpha$ (62 kDa) and $\operatorname{ER} \beta(55 \mathrm{kDa}$ ). Band optical density was adjusted to the corresponding actin band and expressed as a percentage of the nonpregnant (NP) value obtained in the same experiment. $\left({ }^{*} P<0 \cdot 05\right.$ vs NP).

nonpregnant controls considered as 100\% (Fig. 6C). In the early postpartum period, LV BNP mRNA returned to control levels.

\section{Expression of natriuretic peptide receptors}

Figure 7 presents the results of RT-PCR analysis of GC-A, GC-B, and NPR-C mRNA expression in LV of nonpregnant and pregnant rats in different stages of gestation and postpartum. Notably, compared with nonpregnant controls, GC-A mRNA, transducing ANP and BNP signals, was downregulated on days 14 and 21 of pregnancy, and in the early postpartum period (Fig. 7A). GC-B mRNA was also significantly lower in the LV at day 21 and postpartum than in nonpregnant controls (Fig. 7B). In contrast, NPR-C mRNA responsible for natriuretic peptide clearance (Fig. 7C) was significantly higher on day 21 of gestation.

\section{Discussion}

The present study demonstrates that LV weight positively correlates with body weight gain during early gestation 

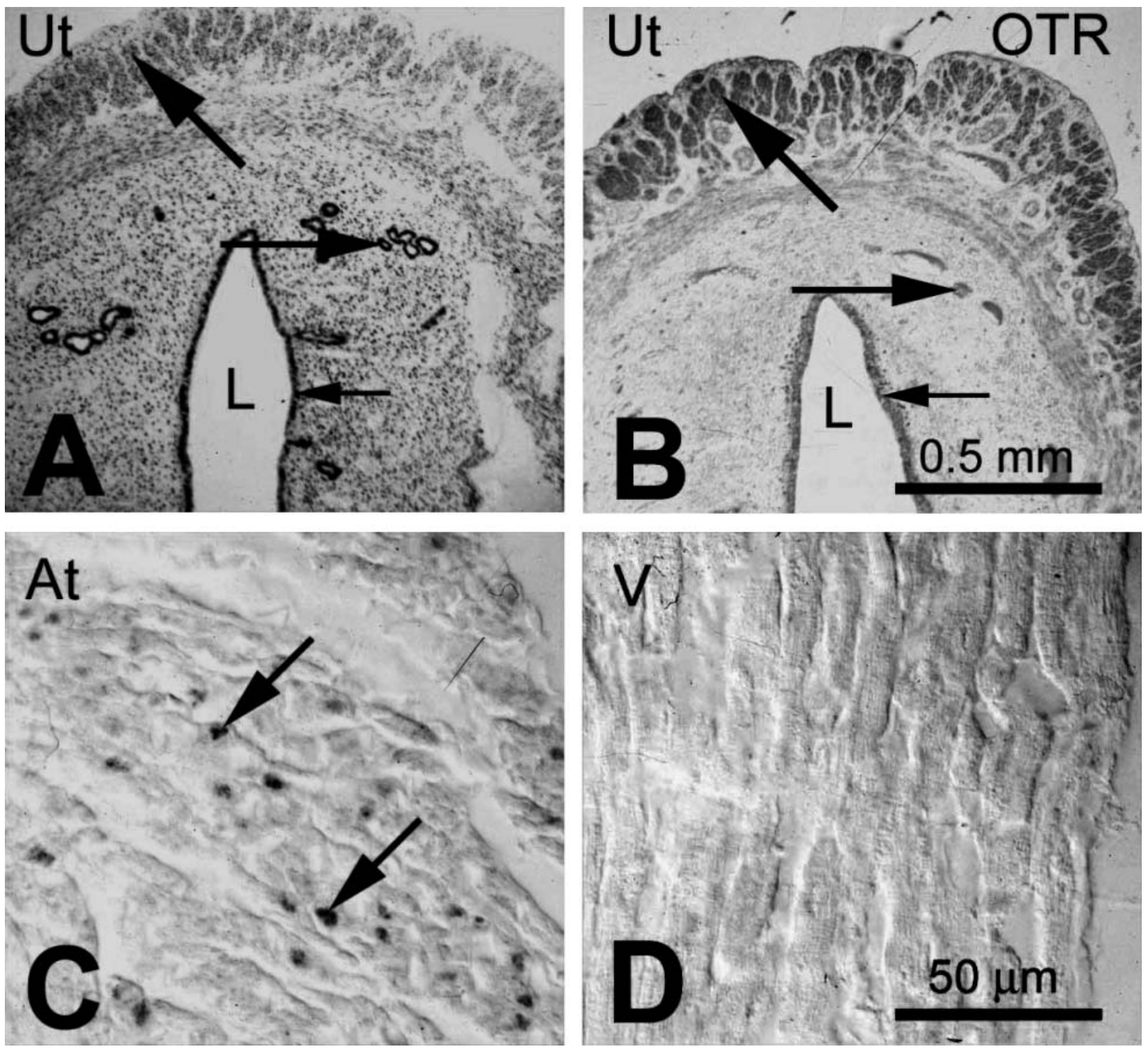

Figure 5 Immunocytochemical localization of $\operatorname{ER} \alpha(A, C$ and $D)$ in the rat uterus $(\mathrm{Ut})$ and heart atrium (At) and ventricle (V). (B) Comparable immunocytochemical staining for oxytocin receptor (OTR) in the uterus is shown around the uterine lumen (L), and within epithelial cells (small arrow), uterine glands (medium arrow) and myometrium smooth muscles (large arrow). Cell nuclei within numerous atrial cardiomyocytes displayed ER $\alpha$ immunoreactivity (arrows in C). Much less, if any, ER $\alpha$ immunoreactivity could be seen in the heart ventricle (D). Magnification $(A$ and $B) \times 54$; $(C$ and $D) \times 540$.

and postpartum, but not at term. LV cGMP increases by day 14 of pregnancy in parallel to elevations of eNOS, iNOS, ER $\alpha$ and OTR proteins, but not with the expression of $\operatorname{ER} \beta$, natriuretic peptides and their receptors. At term, LV cGMP decreases as does the expression of cardiac genes involved in particulate and soluble GC activities. These include natriuretic peptides, their GC receptors, eNOS, iNOS, and OTR. In contrast, the ventricular NPR-C transcript is elevated, suggesting that augmented cardiac natriuretic peptide clearance occurs at term. At postpartum, the cGMP-generating systems are activated, in parallel to a gradual decrease in cardiac hypertrophy.

It is established that cardiac adaptations occur in pregnancy. The LV increases in mass to preserve contractile function when cardiac workload is increased to accommodate pregnancy-associated plasma volume expansion (Churchill et al. 1980, Atherton et al. 1982, Barron 1987). Vascular and cardiac adaptations during pregnancy are influenced by reproductive hormones. The actions of estrogens and progesterone are mediated by specific 


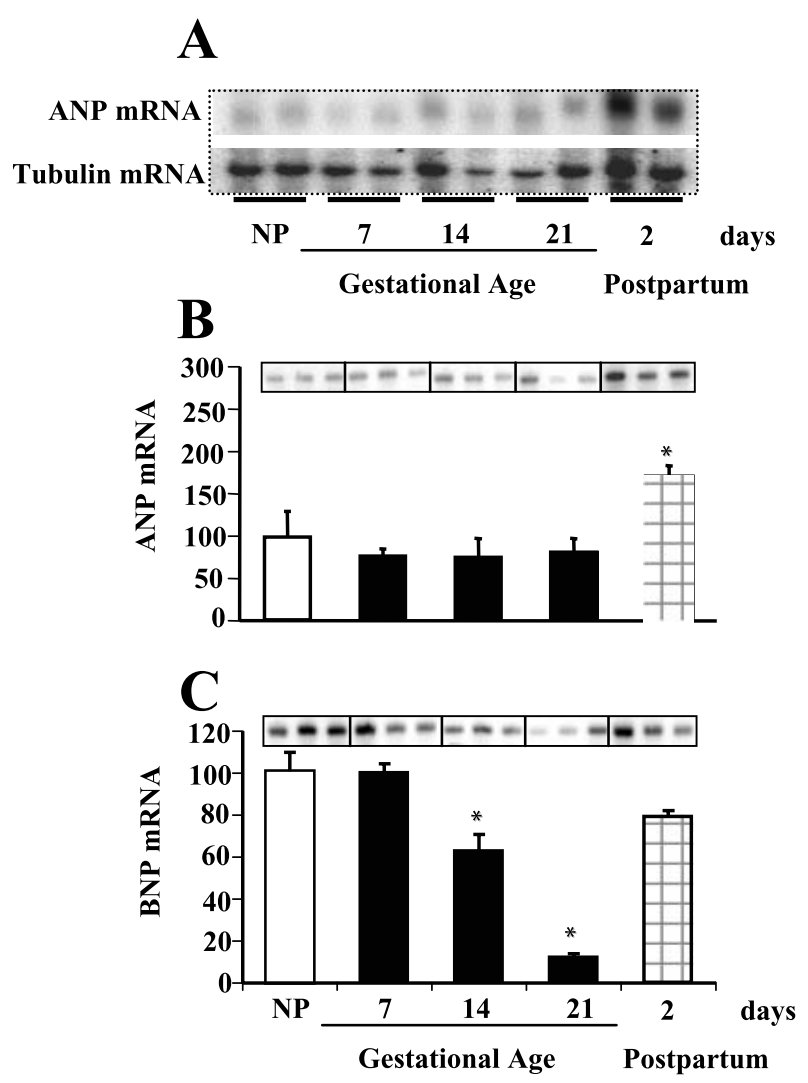

Figure 6 Effect of rat gestation and early postpartum on atrial natriuretic peptide (ANP) expression in left ventricles as demonstrated by Northern blot (A) and RT-PCR (B). RT-PCR was also used for semiquantitative measure of BNP mRNA (C). The RT-PCR products were separated by electrophoresis in $1.5 \%$ agarose, and then quantified by Phosphorlmager software (Molecular Dynamics), and the results were adjusted as the ratio of the signal given by bands of ANP or BNP to the corresponding $18 \mathrm{~S}$ band. Values are mean \pm S.E.M. adjusted to nonpregnant (NP) values (100\%). $n=6$ each; ${ }^{*} P<0 \cdot 05$ vs NP.

binding sites in vascular tissue and in the heart. Their hormonal effects include changes in the synthesis or release of cardiac natriuretic peptides, and in the oxytocin system (Mukaddam-Daher et al. 2002, Wang et al. 2003) as well as NOS and cGMP regulation (Weiner et al. 1994, Linke et al. 2002). In addition, direct interaction between these systems may also be involved in pregnancy-associated cardiac remodeling.

Parallel changes of the expression of LV NOS and OTR were observed during gestation and postpartum. These findings are consistent with OTR influencing NO activity, as previously demonstrated in the dog heart (Mukaddam-Daher et al. 2001), and with the predominant expression of OTR in endothelial cells of coronary arteries, providing a morphologic basis for eNOS and OTR interactions in the heart chambers (Jankowski et al. 2004).

An earlier report indicates that eNOS is transiently elevated during pregnancy in rats, and the increase is
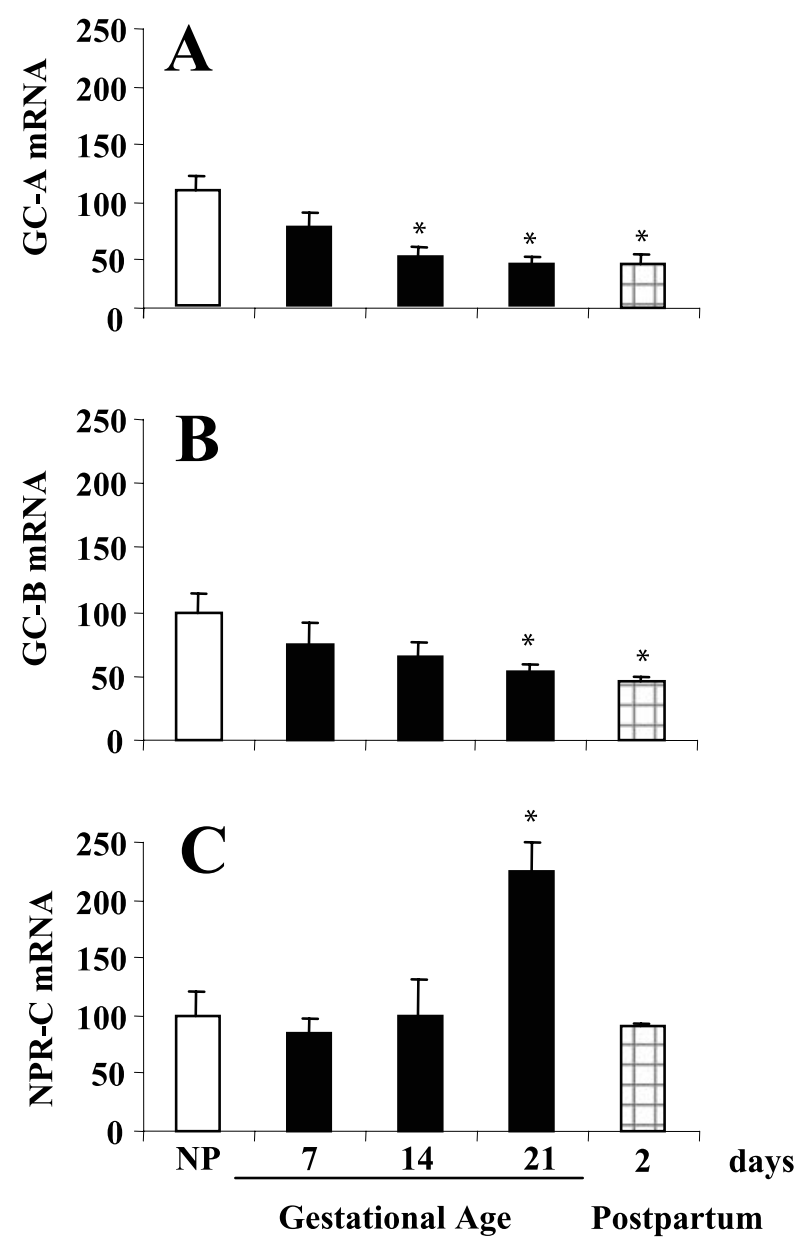

Figure 7 Relative quantification of natriuretic peptide receptor mRNA in left ventricle of rats during gestation and early postpartum by RT-PCR. The separated RT-PCR products were quantified by Phosphorlmager software, and the results were adjusted as the ratio of the signal given by bands of GC-A (A), GC-B (B) and NPR-C (C) to the corresponding $18 \mathrm{~S}$ band. Values are mean \pm S.E.M. adjusted to nonpregnant (NP) values (100\%). $n=6$ each; ${ }^{*} P<0 \cdot 05$ vs NP.

associated with enhanced NO-dependent control of myocardial oxygen consumption at a time when cardiac output is augmented (Linke et al. 2002). Despite a significant increase in eNOS protein expression at day 7 of pregnancy, the investigators observed a nonsignificant trend toward increased myocardial oxygen consumption. Similarly, in the present study, at day 7 of gestation, LV cGMP tended only to increase, despite the significant increases in eNOS proteins. There is no explanation for this lack of parallelism between eNOS and cGMP production. A delay in pregnancy-associated eNOS phosphorylation is a plausible explanation that remains to be proven.

Interestingly, we found that cGMP increased in the LV at day 14 of gestation in parallel with increments of eNOS and OTR, but low expression of GC-A and 
GC-B mRNAs. Downregulation of cardiac natriuretic peptide receptors in LV during pregnancy may be physiologically required to control the negative inotropic activity of natriuretic peptides and to allow the development of pregnancy-induced LV hypertrophy. The mechanism of low expression of GC-A and GC-B mRNAs in this period is not known; however, it may be explained by two hypotheses. First, alterations of female steroids during pregnancy can downregulate natriuretic peptide receptors in several organs (Vaillancourt et al. 1997, 1998). The presence of ERs in the isolated cardiac myocytes and fibroblasts (Grohe et al. 1997) and the fact that these cells contain functional natriuretic peptide receptors suggest that ERs may be involved in pregnancy-mediated changes in the heart. The present ICC data indicate that the density of ERs receptors is much lower in cardiac ventricles than in atria. However, these receptors are functional and stimulate ANP expression and cGMP production in cultured rat cardiomyocytes (Babiker et al. 2004). We have demonstrated that $\operatorname{ER} \alpha$, but not $\operatorname{ER} \beta$, changes during pregnancy. These ER $\alpha$ receptors are, to some extent, upregulated at midgestation in association with similar cGMP elevation. We have already demonstrated that ovarian natriuretic peptide receptors may be a target of estrogen action (Jankowski et al. 1997, Gutkowska et al. 1999). A similar effect in the heart may be proposed where natriuretic peptide receptors exert their physiologic effect on both myocytes and nonmyocytes (Cao \& Gardner 1995), and where natriuretic peptide-signaling events have been detected in both cell types. Second, it has already been shown that downregulation at the level of GC-A transcription appears to depend on intracellular increases of cGMP, and not on the natriuretic peptide ligand itself (Cao \& Gardner 1995). Functional analysis of the GC-A promoter has demonstrated that long-term negative regulation of GC-A occurs via a putative cGMPresponsive element located at more than $1 \mathrm{kbp}$ upstream of the transcription start site (Roubert et al. 1987, Tremblay et al. 2002).

The importance of cGMP in the control of transient LV hypertrophy and the changes in contractility during pregnancy remain to be clarified. Evidence from animal and human studies suggest that the cGMP signaling pathway is gestationally regulated (Weiner et al. 1994, Linke et al. 2002). We observed that, at term, LVcGMP declined below nonpregnant control levels, confirming the previous report by Weiner et al. (1994). This decrease in cGMP may have resulted from downregulated natriuretic peptides and their GC receptors, as well as upregulated clearance receptors, which act as a buffering system, reducing the effective pool of natriuretic peptides. Decline of LV OTR, eNOS, iNOS and ER $\alpha$, and, as we have reported previously, plasma ANP (Mukaddam-Daher et al. 2002) may also contribute to cGMP reduction in the LV. The reduced levels of cGMP at term favor a shift of balance toward enhanced heart work at the onset of labor.
Therefore, cGMP may play an important role in maintaining cardiac quiescence during the final period of pregnancy, and a decrease in cGMP at term may contribute to the increase in heart rate and contractility during active labor.

Finally, an important and still unresolved issue is whether cGMP produced by particulate versus soluble GC acts differently inside the cells. For instance, the increase in cGMP mediated by ANP, but not by NO, prevents cardiomyocyte hypertrophy (Horio et al. 2000). It has also been shown that particulate GC-A, but not soluble GC, has potent effects on plasma membrane control of the calcium ATPase pump (Zolle et al. 2000). A recent study has also demonstrated that ANP/GC-A, but not NO/ soluble GC, stimulates the translocation of PKG I to the plasma membrane (Airhart et al. 2003). It is hypothesized that cGMP-mediated signaling is compartmentalized within cells targeted by $\mathrm{NO}$ and natriuretic peptides (Kuhn 2003).

In conclusion, these findings imply that during pregnancy, LVNOS and natriuretic peptide systems exert direct actions on the heart, and are thus involved in adaptation to pregnancy-associated volume alterations.

\section{Acknowledgements}

We are grateful to Dr M Marcinkiewicz, for critical discussion and help in the immunocytochemistry experiment. We acknowledge the secretarial assistance of Mrs Antoinette Paolitto and the editorial work of Mr Ovid Da Silva.

\section{Funding}

This work was supported by grants from the Canadian Institutes of Health Research (MT-11674, MOP-62901 to J G and S M-D, as well as MT-15049, MOP-53217 to $M J$ and $J$ G), and the Canadian Heart and Stroke Foundation to J G and S M-D. There is no conflict of interest in this research.

\section{References}

Airhart N, Yang Y-F, Roberts CT \& Silberbach M 2003 Atrial natriuretic peptide induces natriuretic peptide receptor-cGMPdependent protein kinase interaction. Journal of Biological Chemistry 278 38693-38698

Atherton JC, Dark JM, Garland HO, Morgan MRA, Pidglon J \& Soni S 1982 Changes in water and electrolyte balance, plasma volume and composition during pregnancy in the rat. Journal of Physiology 330 81-83.

Babiker FA, De Windt LJ, van Eickels M, Thijssen V, Bronsauer JP, Grohé C, van Bilsten M \& Doevendans PA 2004 17 $\beta$-Estradiol antagonized cardiomyocyte hypertrophy by autocrine/paracrine 
stimulation of a guanylyl cyclase A receptor-cyclic guanosine monophosphate-dependent protein kinase pathway. Circulation 109 269-276.

Barouch LA, Harrison RW, Skaf MW, Rosas GO, Cappola TP, Kobeissi ZA, Hobai IA, Lemmon CA, Burnett AL, O’Rourke B, Rodriguez ER, Huang PL, Lima JA, Berkowitz DE \& Hare JM 2002 Nitric oxide regulates the heart by spatial confinement of nitric oxide synthase isoforms. Nature 416 337-339.

Barron WM 1987 Volume homeostasis during pregnancy in the rat. American Journal of Kidney Diseases 9 296-302.

de Bold AJ, Ma KK, Zhang Y, de Bold ML, Bensimon M \& Khoshbaten A 2001 The physiological and pathophysiological modulation of the endocrine function of the heart. Canadian Journal of Physiology and Pharmacology 79 705-714.

Brown LA, Nunez DJ \& Wilkins MR 1993 Differential regulation of natriuretic peptide receptor messenger RNAs during the development of cardiac hypertrophy in the rat. Journal of Clinical Investigation 92 2702-2712.

Cao L \& Gardner DG 1995 Natriuretic peptides inhibit DNA synthesis in cardiac fibroblasts. Hypertension 25 227-234.

Churchill SE, Bengele HH \& Alexander EA 1980 Sodium balance during pregnancy in the rat. American Journal of PhysiologyRegulatory, Intergrative and Comparative Physiology 239 R143-R148.

Granger JP 2002 Maternal and fetal adaptations during pregnancy: lessons in regulatory and integrative physiology. American Journal of Physiology - Regulatory, Integrative, and Comparative Physiology 283 R1289-R1292.

Grohe C, Kahlert S, Lobbert K, Stimpel M, Karas RH, Vetter H \& Neyses L 1997 Cardiac myocytes and fibroblasts contain functional estrogen receptors. FEBS Lett 416 107-112.

Gutkowska J, Jankowski M, Sairam MR, Fujio N, Reis AM, Mukaddam-Daher S \& Tremblay J 1999 Hormonal regulation of natriuretic peptide system during induced ovarian follicular development in the rat. Biology of Reproduction 61 162-170.

Gyurko R, Kuhlencordt P, Fishman MC \& Huang PL 2000 Modulation of mouse cardiac function in vivo by eNOS and ANP. American Journal of Physiology-Heart and Circulatory Physiology 278 H971-H981.

Horio T, Nishikimi T, Yoshihara F, Matsuo H, Takishita S \& Kangawa K 2000 Inhibitory regulation of hypertrophy by endogenous atrial natriuretic peptide in cultured cardiac myocytes. Hypertension 35 19-24.

Jankowski M, Reis AM, Mukaddam-Daher S, Dam TV, Farookhi R \& Gutkowska J 1997 C-type natriuretic peptide and the guanylyl cyclase receptors in the rat ovary are modulated by the estrous cycle. Biology of Reproduction 56 59-66.

Jankowski M, Rachelska G, Donghao W, McCann SM \& Gutkowska J 2001 Estrogen receptors activate atrial natriuretic peptide in the rat heart. PNAS 98 11765-11770.

Jankowski M, Danalache B, Wang D, Bhat P, Hajjar F, Marcinkiewicz M, Paquin J, McCann SM \& Gutkowska J 2004 Oxytocin in cardiac ontogeny. PNAS 101 13074-13079.

Kishimoto I, Rossi K \& Garbers DL 2001 A genetic model provides evidence that the receptor for atrial natriuretic peptide (guanylyl cyclase-A) inhibits cardiac ventricular myocyte hypertrophy. PNAS 98 2703-2706.

Koller KJ, Lowe DG, Bennett GL, Minamino N, Kangawa K, Matsuo H \& Goeddel DV 1991 Selective activation of the B natriuretic peptide receptor by C-type natriuretic peptide (CNP). Science 252 120-123.

Kuhn M 2003 Structure, regulation, and function of mammalian membrane guanylyl cyclase receptors, with a focus on guanylyl cyclase-A. Circulation Research 93 700-709.

Linke A, Li W, Huang H, Wang Z \& Hintze TH 2002 Role of cardiac eNOS expression during pregnancy in the coupling of myocardial oxygen consumption to cardiac work. American Journal of Physiology-Heart and Circulatory Physiology 283 H1208-H1214.

Mukaddam-Daher S, Yin YL, Roy J, Gutkowska J \& Cardinal R 2001 Negative inotropic and chronotropic effects of oxytocin. Hypertension 38 292-296.

Mukaddam-Daher S, Jankowski M, Wang D, Menaouar A \& Gutkowska J 2002 Regulation of cardiac oxytocin system and natriuretic peptide during rat gestation and postpartum. Journal of Endocrinology 175 211-216.

Nakao K, Itoh H, Suga S, Ogawa Y \& Imura H 1993 The natriuretic peptide family. Current Opinion in Nephrology and Hypertension 2 45-50.

Roubert P, Lonchampt MO, Chabrier PE, Plas P, Goulin J \& Braquet P 1987 Down-regulation of atrial natriuretic factor receptors and correlation with cGMP stimulation in rat cultured vascular smooth muscle cells. Biochemical and Biophysical Research Communications 148 $61-67$.

Simmons LA, Gillin AG \& Jeremy RW 2002 Structural and functional changes in left ventricle during normotensive and preeclamptic pregnancy. American Journal of Physiology-Heart and Circulatory Physiology 283 H1627-H1633.

Slangen BF, Out IC, Verkeste CM \& Peeters LL 1997 Hemodynamic changes in early pregnancy in chronically instrumented, conscious rats. American Journal of Physiology-Heart and Circulatory 272 H695-H700.

Suga S, Nakao K, Hosoda K, Mukoyama M, Ogawa Y, Shirakami G, Arai H, Saito Y, Kambayashi Y \& Inouye K 1992 Receptor selectivity of natriuretic peptide family, atrial natriuretic peptide, brain natriuretic peptide, and C-type natriuretic peptide. Endocrinology 130 229-239.

Tremblay J, Desjardins R, Hum D, Gutkowska J \& Hamet P 2002 Biochemistry and physiology of the natriuretic peptide receptor guanylyl cyclases. Molecular and Cellular Biochemistry 230 31-47.

Trochu JN, Bouhour JB, Kaley G \& Hintze TH 2000 Role of endothelium-derived nitric oxide in the regulation of cardiac oxygen metabolism: implications in health and disease. Circulation Research 87 1108-1117.

Vaillancourt P, Omer S, Palfree R, Varma DR \& Mulay S 1997 Downregulation of adrenal atrial natriuretic peptide receptor mRNAs and proteins by pregnancy in rats. Journal of Endocrinology 155 523-530.

Vaillancourt P, Omer S, Deng XF, Mulay S \& Varma DR 1998 Differential effects of rat pregnancy on uterine and lung atrial natriuretic factor receptors. American Journal of Physiology-Endocrinology and Metabolism 274 E52-E56.

Vuolteenaho O \& Ruskoaho H 2003 Gender matters: estrogen protects from cardiac hypertrophy. Trends in Endocrinology and Metabolism 14 52-54.

Wang D, Gutkowska J, Marcinkiewicz M, Rachelska G \& Jankowski M 2003 Genistein supplementation stimulates the oxytocin system in the aorta of ovariectomized rats. Cardiovascular Research $\mathbf{5 7}$ 186-194.

Weiner CP, Knowles RG \& Moncada S 1994 Induction of nitric oxide synthases early in pregnancy. American Journal of Obstetrics and Gynecology 171 838-843.

Zolle O, Lawrie AM \& Simpson AW 2000 Activation of the particulate and not the soluble guanylate cyclase leads to the inhibition of $\mathrm{Ca}^{2+}$ extrusion through localized elevation of cGMP. Journal of Biological Chemistry 275 25892-25899.

Received 12 October 2004 Accepted 19 October 2004 